\title{
Alocação e Realocação do Direito de Uso da Água: Uma Proposta de Modelo de Mercado Limitado no Espaço
}

\author{
José Nilson B. Campos, Ticiana Marinho de C. Studart \\ Departamento de Engenharia Hidráulica e Ambiental - Universidade Federal do Ceará - Campus do Pici - Bloco 713 \\ 60451-970 Fortaleza, CE - Fone (85) 288-9623 - Fax (85)288-9627 - nilson@ufc.br, ticiana@ufc.br
}

Antônio Martins da Costa

Secretaria dos Recursos Hídricos do Estado do Ceará - martins@srh.ce.gov.br

Recebido: 17/10/01 - revisão: 22/01/02 - aceito: 13/05/02

\section{RESUMO}

A crescente demanda por água de boa qualidade em um contexto de limitações na oferta tem motivado à sociedade a pesquisar novos modelos legais e institucionais de gestão de recursos hídricos. A formulação e aperfeiçoamento de modelos que conduzam o processo de alocação de águas a um maior nível de eficiência tem recebido uma especial atenção por parte de pesquisadores e de formuladores de políticas de água. um desses modelos, o mercado de águas, tem sido objeto de muitos debates e polêmicas. O mercado tem sido aplicado em várias partes do mundo, como no Chile, na Austrália e no oeste dos Estados Unidos. O artigo apresenta conceitos teóricos sobre o processo de alocação e realocação de águas e apresenta um modelo no qual o mercado de águas está inserido.

Palavras-chave: gestão de recursos hídricos; alocação de águas.

\section{ESCOLHA SOB ESCASSEZ: O PROBLEMA CENTRAL}

Houve um tempo em que os profissionais de recursos hídricos eram predominantemente engenheiros civis. Os aumentos da demanda por água eram supridos por incremento na oferta, provenientes da construção de grandes reservatórios ou ainda pelo aumento da exploração das águas subterrâneas, com a perfuração de mais e mais poços profundos. Ao mesmo tempo em que aumentava a oferta para atender à crescente demanda, ações de engenharia executadas sem os necessários cuidados ambientais, resultaram em graves problemas para a qualidade das águas e para o meio ambiente.

Nesse novo cenário, foi-se a ilusão que a tecnologia seria capaz de suprir todos os desejos da sociedade. As limitações dos recursos naturais, particularmente dos recursos hídricos, fizeram com que fossem desenvolvidas técnicas como a gestão da demanda, a avaliação de impactos

ambientais e a participação da sociedade nas tomadas de decisões.

Do ponto de vista das ciências econômicas, o maior desafio está no fato de não existirem recursos ilimitados, que permitam atender todas as demandas da sociedade, resultando na necessidade do estabelecimento de métodos para a convivência com essas limitações. Muitas teorias foram e continuam sendo desenvolvidas para tratar da questão da alocação de recursos em regime de escassez.

Nesse novo contexto, surgem questões como: Qual a melhor maneira de alocar os limitados recursos naturais? Será o mercado, o mecanismo ideal para governar todas as alocações de águas? Será que o mercado é sempre indesejável como instrumento de alocação de água? No Semi-Árido, onde a escassez de água é crônica, haverá espaço legal e institucional para utilizar o mercado como instrumento de alocação?

Essas são as questões tratadas no presente artigo. São estudadas possibilidades e condicionantes do estabelecimento de um mercado de águas como ferramenta de realocação de águas, com foco na irrigação.

\section{BASE CONCEITUAL EM ALOCAÇÃO DE ÁGUAS}

Apresenta-se nessa seção um resumo de conceitos básicos do processo de alocação de águas. 
São enfocados os processos que formam um sistema de alocação que engloba desde as atividades de avaliação das disponibilidades até as atividades de realocação, as quais somente têm lugar após o comprometimento de todos os recursos.

Classes de uso - São as modalidades nas quais os técnicos de recursos hídricos dividem os usos da água. As principais classes são: usos consuntivos, quando há consumo efetivo da água; uso não consuntivo, quando não há consumo de água. Entre os usos consuntivos os mais importantes são: o abastecimento urbano, a irrigação e o abastecimento industrial. Entre os usos não consuntivos estão a recreação, a geração de energia elétrica e a assimilação de esgotos.

Usuário - Aquele que, por direito proveniente de uso, frui as utilidades da coisa. No caso em pauta, o usuário não é, necessariamente, uma pessoa física ou uma empresa. Um conjunto de pessoas e/ou empresas, podem formar um único usuário com vistas à alocação de águas, como, por exemplo, um distrito de irrigação.

Alocação - Representa o ato de distribuir um determinado recurso entre usuários. O usuário passa a ter um direito de uso daquela quantidade que lhe foi alocada.

Alocação inicial - Representa a primeira distribuição, entre os diversos usuários, da totalidade das disponibilidades hídricas conhecidas. Normalmente acontece quando da organização do sistema institucional de gestão de recursos hídricos.

Realocação - Representa o ato de redistribuir um determinado recurso, anteriormente alocado. A realocação procura redirecionar o uso do recurso escasso para novo objetivo, procurando acompanhar a dinâmica da sociedade. O mercado de águas é um instrumento de realocação.

Transferência temporária da água - Ocorre quando o titular do direito de uso da água transfere, em caráter temporário, uma parte ou a totalidade das águas sobre a qual tem direito. Essa transferência pode se dar, por exemplo, em momentos de secas.

Transferência do direito de uso da água - Ocorre quando o titular do direito de uso da água transfere, em caráter definitivo, uma parte ou a totalidade das águas sobre a qual tem direito. Essa transferência requer uma sanção legal para assegurar ao comprador, definitivamente, o direito de uso da água.

Custos de transações de águas no mercado - As transferências de direito de usos da água no mercado envolvem um custo que, por vezes, chega a inviabilizálas. Os principais custos são: i) custos da infra-estrutura física necessária para medir e transportar a água, incluindo as perdas por infiltração e evaporação, quando houver; ii) custos da procura de compradores e de negociação do contrato; iii) custo de validar a posse legal do direito de uso (Hearne \& Easter, 1995).

\section{REALOCAÇÃO E MERCADO DE ÁGUA - A EXPERIÊNCIA DE VÁRIOS PAIÍSES}

A literatura aborda com grande ênfase a experiência do oeste americano, onde uma série de fatores atuando conjuntamente, tais como crescimento populacional, escassez de água e alocação baseada no critério da antigüidade - a conhecida first in time, first in rightresultaram em um mercado com regras bem definidas. Todavia, existem outros mercados de água estabelecidos fora da fronteira americana.

No Paquistão e no norte da Índia, transferências de água entre irrigantes situados ao longo de um mesmo curso d'água ou canal são bastante comuns. Os irrigantes têm direito a um determinado tempo de bombeamento da água do canal de irrigação que os abastece e trocam entre si seus tempos de bombeamento sem nenhuma autorização formal (Easter, 1986). O volume de água efetivamente recebido pelo irrigante varia em função da vazão do canal. Entretanto, qualquer que seja a vazão do canal, ela será do irrigante agendado para aquele horário. Estas negociações, no entanto, precisam da concordância dos irrigantes situados entre os lotes das partes envolvidas, $o$ que muitas vezes dificulta o processo de transação. Como as negociações são informais, as autoridades não podem intervir. Ainda assim, as transferências são numerosas, o que indica que ambos - comprador e vendedor se julgam beneficiados (Easter, 1986).

O Chile é um dos poucos países em desenvolvimento que encorajam o mercado de água, o qual é mais ativo nas regiões norte e central do 
país, onde a água é escassa e os custos de transação baixos. O Código Nacional de Águas, instituído em 1981, estabelece que a água é um bem público, mas permite a transferência do seu direito de uso, seja para usos consuntivo ou não-consutivo, seja para água superficial ou subterrânea (Easter \& Hearne, 1995).

No México, empréstimos e venda de água entre fazendeiros são comuns e existem desde o tempo que eram considerados ilegais. Contudo, a situação mudou em 1992, quando a nova lei das águas foi promulgada, descentralizando a gestão dos recursos hídricos do país e permitindo a transferência, entre irrigantes individuais, da concessão pelos usos da água (Hearne \& Trava, 1997).

Outro exemplo de mercado de água é o estabelecido há muitos séculos em Alicante, na Espanha, envolvendo uma área de 3.700 ha, incluindo o reservatório Tibi, construído no final do Século XVI. Os direitos de água são dissociados da propriedade da terra e, embora se baseiem em tempo de irrigação, são convertidos em unidades volumétricas, devido à permanência das vazões liberadas para o canal de irrigação, o qual é mantido com uma vazão constante de $150 \mathrm{l} / \mathrm{s}$, com exceção dos anos de seca (Easter \& Hearne, 1995). Os direitos são negociados em leilões, que ocorrem todas as manhãs de domingo, na província de San Juan. Os leilões também são utilizados como forma de realocação de água em Victoria, Austrália (Simon \& Anderson, 1990).

Um sistema mais centralizado de transferência temporária de quantidades finitas de água é o banco de água, que estabelece uma conta única para o total de água vendida e comprada, intermediando as transações entre potenciais vendedores e compradores de água. Alguns bancos de água funcionam em caráter permanente, como o Idaho Water Bank Supply, enquanto outros são temporários, atuando apenas em períodos críticos, como os criados na Califórnia durante as secas de 19761977 e 1987-1991 (Bhatia et al., 1993).

$\mathrm{Na}$ Chapada do Araripe, na região do Cariri cearense, existe um processo totalmente peculiar de alocação e realocação de águas: as águas das fontes - em especial a da Batateiras - foram partilhadas entre proprietários de terras ali situadas, por documentos formalizados em 1855. Entre as regras estabelecidas está a possibilidade de: 1) vender-se a titularidade do direito em caráter permanente; 2 ) vender por tempo determinado e por volume determinado; 3 ) caso as vazões das fontes diminuíssem, a perda de direito ocorreria de jusante para montante (Kemper et al., 1999). Durante os últimos cento e cinqüenta anos, o processo evoluiu pacificamente, sem grandes conflitos entre os usuários. A validade do modelo, no entanto, vem sendo questionada por juristas, diante da nova ordem jurídica do país (Araújo Sá e Campos, 2001). Os usuários, no entanto, têm a percepção de que são donos legais da água, em função dos direitos adquiridos e documentação pertinente, não estando dispostos a abrirem mão de seus direitos (Brito, 2001).

\section{UM MODELO DE ALOCAÇÃO DE ÁGUAS}

Em um exercício didático, à guisa de contribuição para o aprimoramento de novos modelos institucionais e legais de gestão de águas, concebeu-se um modelo teórico que representa a seqüência de implementação de um mercado de águas limitado à uma determinada região.

Esse modelo pode ser construído em quatro fases: 1) diagnóstico da situação atual; 2) definição dos totais a alocar; 3) alocação das disponibilidades e 4) definição de critérios para realocação.

No diagnóstico, seriam avaliadas todas as disponibilidades e potencialidades hídricas, assim como também o comprometimento das disponibilidades com os consumos existentes e projetados.

Em um segundo momento, seriam definidos os totais de água a outorgar. Posteriormente, se faria uma alocação das disponibilidades e, em um quarto momento, a sociedade, com todos os recursos hídricos alocados, buscaria um mecanismo para transferir estes recursos já alocados para um outro uso (ou usuário) que deles fizesse melhor uso, sob o ponto de vista do conjunto da sociedade.

\section{Diagnóstico das disponibilidades}

O diagnóstico das disponibilidades hídricas é essencialmente técnico. Nele, o analista procura avaliar, com base em dados hidrológicos, as relações entre as disponibilidades hídricas e as diferentes regras de operação dos sistemas hídricos existentes, naturais ou artificiais. Nessa fase, procede-se ao estudo das disponibilidades, em termos de águas já alocadas e de águas passíveis de serem alocadas.

Os técnicos em recursos hídricos não devem perder de vista que estão gerando informação para uma futura tomada de decisão por políticos e 
pela sociedade. O problema é complexo e seu entendimento real, do ponto de vista teórico, somente está ao alcance de especialistas. Assim, é necessária uma síntese do diagnóstico de disponibilidades hídricas redigido em linguagem inteligível pelos usuários.

Valores como vazão regularizada e vazão mínima heptadial (7 dias) de período de retorno de 10 anos, são altamente variáveis. Ademais, normalmente há deficiência de dados para estimar esses valores. $\mathrm{O}$ bom senso e uma boa formação teórica em Hidrologia e Recursos Hídricos são atributos indispensáveis a que se conduza a bom termo essa tarefa técnica.

A análise também deve incluir as potencialidades pois, embora em um determinado momento todas as disponibilidades possam já estar comprometidas com usos atuais, é possível que haja condições, no futuro, de se aumentar as disponibilidades, através da ativação de potencialidades. Certamente, as disponibilidades estariam associadas à garantia e a qualidade das águas.

$\mathrm{O}$ uso de modelos de redes e técnicas de sistemas de informação geográfica são essenciais à visão do conjunto. Queiróz et al. (2000) desenvolveram um modelo de distribuição para a Vale do Jaguaribe utilizando técnicas de SGI.

\section{Definição dos totais a alocar}

Quanto maiores forem as retiradas de água dos sistemas hídricos, maiores serão as probabilidades de falhas no atendimento das demandas. Aos técnicos, cabe estudar as relações entre os totais de águas retirados dos sistemas hídricos e as respectivas garantias. As conseqüências, positivas e negativas, de usar mais água com uma menor garantia ou, alternativamente, usar menos água com maior garantia, recaem sobre a sociedade.

Assim, os técnicos são detentores do conhecimento e podem avaliar melhor as conseqüências. A sociedade, por sua vez, beneficiária dos ganhos e perdas em função das decisões tomadas, tem todo o direito de participar diretamente dessas decisões.

O papel dos técnicos é passar as informações da melhor maneira possível para os usuários para que estes tomem a decisão sobre quanta água deve ser outorgada em uma dada bacia hidrográfica. No lado institucional, essa fase está relacionada ao total de água a outorgar. As dificuldades de ordem prática, encontradas na definição desse total, é discutida por Campos e Vieira (1993) para as condições do nordeste semi-árido.

\section{Alocação inicial}

Uma vez definidas as disponibilidades atuais, parte-se para alocar essas disponibilidades entre os diversos usos e usuários. Nessa etapa há o estabelecimento, ou o reconhecimento, de direitos. Assim, a presença de profissionais do segmento jurídico é importante e predominante.

Com relação ao balanço das disponibilidades em água versus direitos de usos da água reconhecidos, três situações podem ocorrer: 1) há mais disponibilidades do que direitos; 2) há mais direitos que disponibilidades e, 3) as disponibilidades e os direitos se eqüivalem.

Na situação 1, onde os totais a alocar são maiores do que as demandas estabelecidas e projetadas, o processo de alocação ainda pode prosseguir, visto que o sistema comporta a entrada de novos usuários. O excedente das disponibilidades poderia ficar com a sociedade, que estabeleceria critérios para a alocação desses excedentes. O leilão de águas tem sido usado em alguns países nessa situação. A conveniência, ou não, desse procedimento deve ser resolvida caso a caso.

Na situação 2, onde os totais a alocar são menores do que demanda estabelecida, a situação seria um pouco mais complicada. Se persistissem todos os direitos de água, o déficit seria suprido por um decréscimo na garantia. Os conflitos seriam mais freqüentes. A sociedade poderia optar por manter os totais a alocar definidos na fase anterior e retirar alguns consumidores do sistema. Haveria a necessidade de negociações entre os usuários e de compensação para os que forem retirados do sistema.

A situação 3, onde direitos e disponibilidades são iguais, caracterizaria o final da fase de alocação inicial. Entretanto, somente por um mero acaso essa igualdade aconteceria. De qualquer maneira, essa situação caracterizaria o limite entre a alocação inicial e a fase de realocações, definidas a seguir.

\section{Realocações}

Quando todas as disponibilidades estão alocadas, e os custos de incremento dessas disponibilidades se tornam muito elevados, passam a funcionar os mecanismos para que as águas sejam redistribuídas de acordo com as mudanças nas 
demandas da sociedade. Essas realocações podem ser procedidas pelo governo ou pelo mercado.

Uma seqüência lógica de operações está representada esquematicamente na Figura 1. Convém ressaltar que há situações reais que devem ser incorporadas ao planejamento operacional como, por exemplo, a construção de novos reservatórios. Essa situação pode ser pensada como uma inserção de águas no sistema, que criaria novos direitos para a sociedade. Haveria um aumento nas disponibilidades hídricas que poderiam ser alocadas de várias maneiras, tais como alocação em função de uma política governamental de caráter social ou alocação por leilão de águas. Seria uma espécie de retorno à fase de alocação inicial.

Concluindo, mesmo havendo situações a serem incorporadas ao modelo teórico de uma estrutura de alocação e realocação, o mesmo permanece válido para o planejamento da organização das disponibilidades hídricas de uma dada bacia hidrográfica. O mercado de água é inserido nesse modelo como um mecanismo institucional de realocação.

Há três condições importantes para aplicação do mercado:

1. a legislação deve permitir ao titular do uso o direito de transferi-lo;

2. os sistemas hídricos devem ser organizados para os processos de alocação e realocação, exercendo o controle através da outorga;

3. as transferências permanentes devem ser informadas e avalizadas pelo órgão gestor que deverá emitir nova outorga para o novo usuário. Esta situação deve figurar na legislação como transferência de outorga.

\section{A FUNCIONALIDADE DO MERCADO DE ÁGUAS}

O funcionamento do mercado nas comercializações de bens de uma maneira geral depende de três componentes básicos: os bens levados a mercado; as partes interessadas em vendê-los e as partes interessadas em comprá-los.

Por exemplo, no mercado imobiliário os três componentes são: os imóveis, pessoas desejosas de adquirir imóveis e pessoas interessadas em vender imóveis. No mercado de águas, por sua vez, estes três componentes são: o direito de uso da água, o interessado em vender o direito e o interessado em comprar esse direito.

$\mathrm{O}$ aspecto quantitativo dos três componentes formadores de um determinado mercado é fator determinante na formação dos preços. Havendo muitos compradores, vendedores e bens, haverá um mercado equilibrado e os preços dos bens nesse mercado serão justos. Nesses casos, diz-se que há uma concorrência perfeita que conduz ao equilíbrio de acordo com a lei da oferta e da procura.

Um aspecto importante no mercado é que cada negócio é acordado entre comprador e vendedor de acordo com a função de utilidade de cada um. O preço pago pelo comprador tem um valor máximo o qual ele está disposto a pagar, enquanto que o preço aceito pelo vendedor tem um valor mínimo o qual ele está disposto a vender.

Situações indesejáveis podem ocorrer quando poucos indivíduos, ou associações destes, são capazes de interferir fortemente na formação de preços, tornando o mercado tendencioso. Essas situações são descritas a seguir.

\section{Situações indesejáveis no mercado}

As situações indesejáveis ocorrem onde poucos indivíduos, ou associações deles, podem influir diretamente na formação do preço de um determinado bem. Essas situações extremas acontecem na concentração de compradores ou de vendedores quando o bem não tem um substituto. São elas: por um lado, o monopólio ou oligopólio e por outro, o monopsônio ou oligopsônio.

Monopólio e oligopólio - Refere-se a uma situação onde o mercado é comandado por um único vendedor, ou poucos vendedores, que monopolizam os preços resultando em um viés no sentido de altos preços. Significa que as pessoas passam a pagar pelo bem um valor bem superior ao que pagariam caso houvesse uma concorrência perfeita.

Monopsônio e oligopsônio - Refere-se a uma situação onde apenas um comprador, ou grupo agindo em acordo, detém o poder de compra de um determinado bem. Nessa situação, há um viés para baixo na formação dos preços.

No caso do mercado de águas, não se encontra na literatura estudos que apontem qualquer preocupação acerca do risco da prática do monopsônio ou oligopsônio. Por outro lado, grande parte das restrições ao mercado de água devem-se ao receio da prática do monopólio ou oligopólio, os quais podem levar a um mau uso do meio ambiente e a um descaso com as necessidades da sociedade, especialmente das parcelas de baixa renda. 


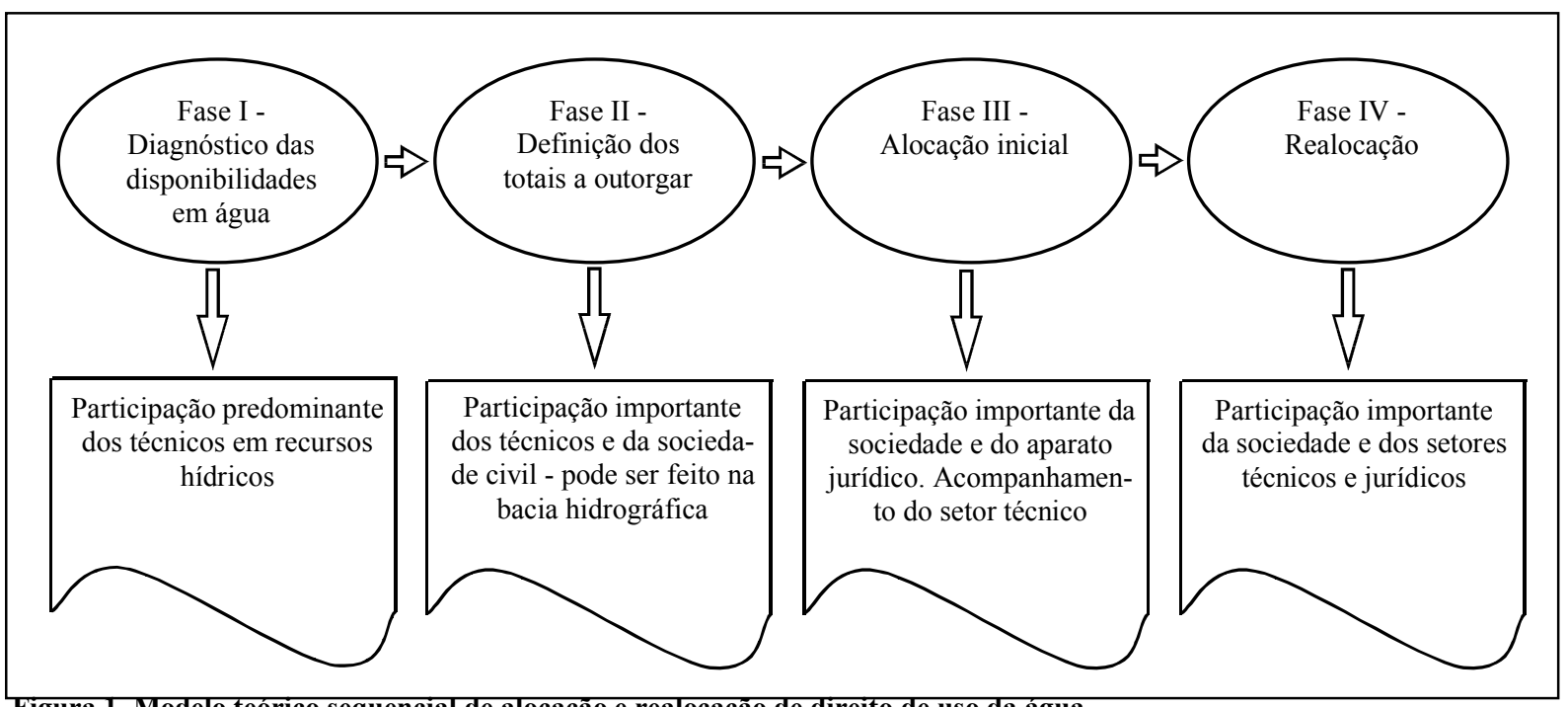

Figura 1. Modelo teórico sequencial de alocação e realocação de direito de uso da água.

\section{O mercado no contexto da gestão da demanda de águas}

No último quartil do século $\mathrm{XX}$, principalmente após a difusão do conceito de desenvolvimento sustentável, governantes, estudiosos e a sociedade em geral, passaram a buscar em medidas não estruturais um novo modelo de gestão de águas. Nessa nova teoria foram firmados princípios e instrumentos de gestão.

Os instrumentos para a gestão da demanda podem ser classificados em três grandes grupos, segundo Brooks (1997) e Bhatia et al. (1993):

- medidas conjunturais;

- incentivos;

- intervenção direta.

As medidas conjunturais são formadas por arranjos legais e institucionais, privatização e políticas macroeconômicas.

Os incentivos podem ser econômicos e não econômicos. Entre os incentivos econômicos estão a tarifa de água, a cobrança pela poluição, o mercado de água, os bancos de água e os leilões de água.

Os incentivos não econômicos podem ser agrupados em voluntários e compulsórios. Entre os compulsórios estão o racionamento através de normas para controle do tempo e da quantidade do fornecimento, as sanções e as restrições por mau uso. Os voluntários têm origem basicamente em campanhas educativas e resultam em disciplinamento dos usuários no sentido da busca de um uso racional e parcimonioso.

$\mathrm{E}$, finalmente, a intervenção direta consiste, entre outras coisas, em promover uma melhor eficiência das redes públicas de distribuição de águas e criação de programas de reúso.

\section{MOTIVAÇÕES E PRÉ-REQUISITOS PARA O MERCADO DE ÁGUAS}

Tecnicamente, o mercado de águas é um instrumento de realocação de águas que busca um uso mais eficiente. Em termos práticos, o bem negociado seria o direito de uso da água, o qual seria transferido do vendedor, titular do direito, para o comprador, que passaria então à condição de titular.

Em termos de tempo, a transação poderia ser permanente ou limitada a um certo período. Em termos de espaço, a institucionalização do modelo poderia se restringir a um país, a um Estado, a uma bacia hidrográfica ou mesmo a uma área específica, dependendo dos costumes, das leis e também das estruturas disponíveis para transferência de águas.

A alocação das águas pelo mercado é justificada na suposição que o mesmo leva a um uso mais eficiente das águas. $\mathrm{O}$ mercado de águas repousa nas mesmas premissas do mercado de bens de uma maneira geral. $\mathrm{O}$ modelo supõe que um usuário que possa promover usos privados mais eficientes da água esteja propenso a pagar pelo direito de uso de outro usuário que faça uso menos eficiente. $\mathrm{O}$ valor máximo que o possível compra- 
dor pagaria estaria limitado pelo valor incremental de seus lucros com o adicional de água. O preço mínimo que o vendedor estaria disposto a aceitar estaria limitado pelo que deixaria de ganhar com a água cujo direito de uso foi vendido (Lanna, 1994).

Aceitando-se a premissa, deve-se avaliar quais as condições necessárias para que o direito de uso da água possa ser tratado como um bem de mercado. Simpson (1993) apresenta seis pré-requisitos que considera desejáveis para o estabelecimento do mercado de águas. São eles:

1. Deve existir um produto definido. Esse produto deve ser passível de ser controlado, medido e trocado como um bem comercial.

2. Deve existir uma demanda para o produto que deve exceder à oferta.

3. O produto deve ser capaz de ser provido quando necessário.

4. O produto deve ter suficiente mobilidade para ser transferido do local de excesso para o local de escassez.

5. Deve haver aceitação pela sociedade envolvida que a livre comercialização do produto é do interesse da sociedade.

6. Deve haver mecanismos de administração e regulamentação que assegurem justiça e equidade.

Simpson (1993) não coloca o atendimento rigoroso e total dos seis pré-requisitos como condição indispensável ao estabelecimento do mercado. Todavia, argumenta que o atendimento mais completo aos prérequisitos citados implica em um melhor funcionamento dos mecanismos do mercado.

\section{POSSIBILIDADES DE REALOCAÇÃO COM MERCADO DE ÁGUAS}

As transferências dos direitos de uso das águas podem se dar de maneira intra-setorial ou intersetorial. A intra-setorial ocorre quando as trocas acontecem dentro do mesmo uso, como por exemplo, entre irrigantes de um mesmo distrito de irrigação (ou de diferentes distritos de irrigação). A intersetorial ocorre, por sua vez, quando acontecem entre diferentes usos, como de irrigação para abastecimento humano, por exemplo.

Quanto ao tempo podem ser temporárias ou permanentes. As temporárias são as que ocorrem somente para suprir um momento de escassez. As permanentes ocorrem quando a transferência se dá no direito de uso e necessita confirmação jurídica.

Uma classificação completa incluiria as transações quanto aos setores e quanto ao tempo, conforme apresentada a seguir:
- Intra-setoriais em caráter provisório.

- Intra-setoriais em caráter permanente.

- Intersetoriais em caráter provisório.

- Intersetoriais em caráter permanente.

Muitas situações seriam possíveis de analisar, visto a diversidade de setores de uso das águas. Para efeito do presente estudo foram avaliadas as situações consideradas mais importantes. Muitas das transações concentraram-se em usos com irrigação, visto tratar-se do setor de maior consumo.

- Tipo 1.Transações temporárias (troca de água):

a. dentro de um mesmo distrito de irrigação, de um mesmo rio e da mesma tomada d'água;

b. entre dois distritos de irrigação, de um mesmo rio, mas de duas tomadas d'água distintas;

c. entre dois distritos de irrigação e de diferentes rios (obras de transposição).

- Tipo 2. Transações permanentes (transferência do direito de uso):

a. dentro de um mesmo distrito de irrigação, de um mesmo rio e da mesma tomada d'água;

b. entre dois distritos de irrigação, de um mesmo rio, mas de duas tomadas d'água distintas;

c. entre dois distritos de irrigação e de diferentes rios (obras de transposição);

d. entre duas bacias hidrográficas distintas (obras de transposição).

Os tipos possíveis de transferência citados são analisados a seguir sob as óticas dos aspectos hidráulicos, da outorga e dos custos de transação.

\section{Transferências temporárias dentro de um mesmo distrito (Tipo 1.a)}

Um dos exemplos mais simples de mercado de águas, pode se dar quando as transferências 
ocorrem dentro de um mesmo distrito de irrigação por tempo limitado. Segundo a nomenclatura de Hearne and Easter (1995), esse tipo é denominado troca de água (exchange of water).

Quanto aos aspectos hidráulicos - Os grandes distritos de irrigação, na maior parte dos casos, captam água de uma única tomada de água em um rio perenizado, ou reservatório, e distribuem entre as unidades agrícolas por uma rede de tubulações ou canais. Vários distritos de irrigação no Estado do Ceará apresentam essa configuração. Dois distritos, o Paraipaba, na bacia hidrográfica do rio Curu, e o Morada Nova, na bacia do rio Banabuiú, podem ser tomados como exemplos:

- Projeto Paraipaba: capta águas do rio Curu em uma barragem de derivação através de uma estação de bombeamento e faz a distribuição entre os lotes individuais, os quais, originalmente dispunham de 3,2 hectares de área agrupados entre setores hidráulicos. Várias transações comerciais ocorreram com os lotes após a emancipação do distrito.

- Projeto Morada Nova: capta água no rio Banabuiu em uma barragem de derivação e faz a distribuição através de uma rede de canais entre os lotes agrícolas individuais. Originariamente os lotes agrícolas foram projetados com áreas variando de 4,0 a 6,0 hectares. A distribuição interna para os lotes individuais era feita por grupos de lotes, denominados quadras hidráulicas, que compartilhavam, através de um sistema de rotação, de uma mesma vazão denominada mão d'água.

Embora não sejam previstas grandes complicações hidráulicas, em situações particulares poderia necessitar alguns arranjos operacionais nas estruturas de partição de água. (usadas no Projeto Morada Nova).

Quanto à outorga - A outorga dos grandes distritos de irrigação pode ser procedida por distrito de irrigação cabendo à administração do distrito proceder a distribuição entre os lotes individuais. Nesse aspecto, não deveria haver grandes complicações burocráticas nos processos de troca. A negociação seria feita dentro do distrito e legitimada também dentro do próprio distrito.
Quanto aos custos de transação - Não se espera grandes custos de transação nessa modalidade de comercialização.

\section{Transferências temporárias entre distritos diferentes e de um mesmo rio (Tipo 1.b)}

Essa modalidade, ainda que relativamente simples do ponto de vista hidráulico, pode apresentar alguma complexidade nos aspectos relacionados à operação e às transações. Um caso particular, ainda simples, que se mostrou operacional, teve e tem lugar nas fontes da Chapada do Araripe (Kemper et al., 1999; Campos e Studart, 2000).

Quanto aos aspectos hidráulicos - No que se refere aos aspectos hidráulicos, no geral, não haveria maiores dificuldades do que as encontradas no caso anterior. Apenas algumas situações particulares poderiam apresentar certa complexidade operacional.

Quanto à outorga - Considerando que a outorga seria concedida a um grupo de usuários, poderia haver complexidade em transferir água de um usuário de um distrito para um outro usuário de um outro distrito. A transação também deveria envolver as administrações dos dois distritos.

Quanto aos custos de transação - Esse tipo de transação, dependendo das distâncias entre os distritos, já pode apresentar custos operacionais significativos, principalmente devido às perdas em trânsito. A negociação já não seria tão direta, podendo resultar em custos nas negociações.

\section{Transferências temporárias entre distritos diferentes e de rios distintos (Tipo 1.c)} condições:

Esse tipo de transação poderia se dar em duas

- quando já existe uma ligação hidráulica entre os dois rios;

- quando não existe ligação hidráulica entre os dois rios.

No caso de existir uma ligação hidráulica entre os dois rios, a análise seria bem semelhante ao Tipo 1.b, já analisado. No caso da não existência de ligações hidráulicas entre os dois rios, o custo da 
obra de ligação provavelmente inviabilizaria a transação, exceto no caso de uma obra muito simples. Somente casos muito especiais, onde a falta de água representasse um desastre econômico ou social seria construída uma obra de porte para uso temporário. Aqui um exemplo é o caso registrado em San Francisco na Califórnia no ano de 1977, onde uma grande adutora foi construída às pressas para livrar a cidade de um colapso.

\section{Transferências permanentes dentro de um mesmo distrito (Tipo 2.a)}

Esse tipo de transação ainda relativamente simples no ponto de vista hidráulico já pode apresentar alguma complexidade do ponto de vista operacional e das transações (o caso das fontes do Batateiras descrito por Kemper et al. (1999) reflete esse tipo de transação). As fontes na Chapada do Araripe, no Ceará, também podem servir de exemplo para este tipo de transação.

Quanto aos aspectos hidráulicos - Apresenta as mesmas características descritas para as transações do Tipo 1.a.

Quanto à outorga - Considerando que a outorga é concedida a um grupo de usuários, não haveria qualquer problema com o órgão concedente da outorga. Apenas a administração do distrito teria que oficializar a troca de direitos. A troca de direito tem que ser realizada pelo órgão concedente.

Quanto aos custos de transação - Tratando-se de uma transação comercial de caráter permanente seria necessário uma formalização em cartório que envolveria algum custo, porém não seriam custos elevados.

\section{Transferências permanentes entre distritos diferentes e de um mesmo rio (Tipo 2.b)}

Essas transações apresentam um maior grau de complexidade quando comparadas às transações anteriormente definidas.

Quanto aos aspectos hidráulicos - Seria semelhante à transação Tipo 1.b, com um pequeno acréscimo. Considerando-se que se trata de uma transferência definitiva, algumas estruturas hidráulicas que não valiam a pena quando considerada a transação de caráter temporário, poderiam tornar-se viáveis.

Quanto à outorga - Há um pouco mais de complicação burocrática que o caso da troca de água em caráter temporário. Se o usuário do perímetro $\mathrm{A}$ vender para um usuário do distrito $\mathrm{B}$ uma vazão $\mathrm{X}$, a outorga do distrito
A deveria ser reduzida de $\mathrm{X}$ enquanto a outorga do distrito B deveria ser acrescida de $\mathrm{X}$ (menos as perdas em trânsito).

Quanto aos custos de transação - Esse tipo de transação, dependendo das distâncias entre os distritos, já pode apresentar custos operacionais significativos, principalmente com as perdas em trânsito. A negociação já não seria tão direta podendo resultar em custos nas negociações. Deve-se considerar também que se o comprador estiver mais próximo da fonte de água que o vendedor haverá uma redução das perdas em trânsito.

\section{Transferências permanentes entre distritos diferentes e de rios distintos (Tipo 2.c)}

A relação entre esse tipo de transação (Tipo 2.c) e a transação Tipo 2.b é semelhante à relação entre a transação Tipo 1.c e a transação Tipo 1.b. O diferencial básico entra essa transação e a transação Tipo 2.b está na existência, ou não, de uma ligação hidráulica entre os dois rios.

Caso haja necessidade de uma obra completa de transposição, dificilmente haverá atrativos econômicos para essa transação. E, mesmo existindo a obra de transposição, há possibilidades de complicações hidráulicas ocasionadas pela localização da área irrigada do comprador em seu distrito de irrigação.

\section{Transferências permanentes entre distritos de irrigação e abastecimento urbano (Tipo 2.d)}

Esse tipo de transação é bastante comum em países desenvolvidos como por exemplo, os Estados Unidos. Muitas cidades do oeste americano, como Los Angeles, compram água de setores de irrigação em caráter temporário, quando há secas, ou permanente, quando há aumento acentuado das demandas.

No Estado do Ceará, em 1993, houve esse tipo de transferência sem, no entanto, ter havido uma transação comercial. Esse episódio ocorreu 
quando a cidade de Fortaleza esteve a beira de um colapso. Foram transferidos grandes volumes de água dos açude Choró Limão e Orós, através do Canal do Trabalhador. Para que essas águas fossem transferidas para Fortaleza, houve intervenção pessoal do governador do Estado. Dessa forma resultaram para as bacias doadoras de água:

- Açude Choró Limão: houve redução dos estoques de água, os quais acarretaram redução das áreas irrigadas nos anos subsequentes (não houve recarga satisfatória do açude).

- Vale do Jaguaribe: houve redução das áreas irrigadas da Chapada do Apodi em 1993.

Quanto aos aspectos hidráulicos - Algumas obras de transposição, como o Canal do Trabalhador (CE), podem ser necessárias. Todavia, os altos valores pagos pela água nos grandes centros urbanos podem viabilizar essas obras.

Quanto à outorga - Vale salientar que a prioridade dada ao consumo humano para uso da água facilitaria em muito a transferência dos direitos de uso da água.

Quanto aos custos de transação - Os maiores custos de transação seriam de ordem hidráulica. No geral, o alto custo das obras de transferência de águas faria com que se buscasse maior eficiência hidráulica nas obras de transposição.

\section{DISCUSSÃO}

O artigo tratou do problema de alocação e realocação de água em condições de escassez. Foram levantadas três questões na primeira seção do texto que, com base no modelo proposto, tentar-se-á dar uma resposta.

\section{Sobre o modelo ideal de alocação}

O modelos de gestão da água, como os modelos políticos, podem oscilar entre um extremo de uma gestão totalmente estatizada a um outro extremo com a gestão inteiramente conduzida pelas forças do livre mercado. Nas águas, como na política, a sabedoria não está nos extremos. Há muitas situações onde a presença do Estado, como gestor, é indispensável. Há também situações onde a gestão pelo o Estado é desnecessária e pode ocasionar uma burocracia ineficiente e indesejável. Em outras palavras, se a alocação, ou realocação, das águas via mercado não deve ser encarada como a panacéia, também não deve simplesmente ser descartada como se fora indesejável em qualquer situação.
Assim, excluindo-se as situações extremas, o melhor modelo deve ser apropriado às condições ambientais, políticas e culturais da região. O modelo ideal não deve ter seus limites delineados por preconceitos. Não deve, porém, se restringir à busca de maximizar o valor econômico da água, especialmente em sociedades desiguais, com grandes segmentos de pobreza. Esse modelo deve ser objeto de uma construção contínua com participação dos políticos, dos técnicos e da sociedade como um todo.

\section{Limitações de ordem legal}

Na texto atual da Lei 9.433/97, considera-se a água como um recurso limitado, essencial à vida e ao desenvolvimento econômico e como um bem dotado de valor econômico. Daí, decorre a necessidade "de uma legislação sintonizada com essa importância e peculiaridades, pois dela depende a implementação de decisões políticas sobre recursos hídricos para que sejam utilizados racionalmente" (Araújo Sá e Campos, 2001).

Assim, em conseqüência de muitas mudanças ocorridas recentemente no arcabouço legal, há, ainda, diversos pontos de divergência entre os juristas especializados em Direito do Meio Ambiente e das Águas. A legalidade do mercado de águas é um desses pontos controversos.

É indiscutível que as águas são bens de domínio dos governos Estadual ou Federal. O uso da água se dá mediante outorga concedida pela instituição de governo competente.

Há também consenso que a aplicação do mercado de águas, sem restrições, é incompatível com o arcabouço legal vigente. Há, contudo, algumas situações particulares que podem ser objeto de análise mais profunda para uma decisão sobre sua legalidade.

Considera-se no presente texto que situações de cessão temporária do direito de uso das águas, no interior de grandes áreas irrigadas que recebem outorga coletiva, não configura qualquer violação às condições de outorga (Tipo 1.a).

O caso onde a transferência é permanente, no interior de um grande distrito de irrigação, com outorga para o conjunto de irrigantes (Tipo 2.a), 
também não implica em violações nas condições da outorga. As transferências internas, nesse caso, devem ser analisadas ante a Lei de Irrigação.

Os demais casos podem ainda ser questionados do ponto de vista legal. Pode haver necessidade de mudanças nas leis para que os mesmos sejam legalmente procedidos. Porém esta discussão, no campo mais técnico, foge ao escopo do presente trabalho. As respostas da legalidade ou não do mercado devem vir da discussão entre juristas.

\section{CONCLUSÕES}

O estudo apresentou uma análise das possibilidades de transações de águas, temporárias ou permanentes, dentro de uma estrutura de mercado de água para o Estado do Ceará. As análise procedidas referem-se aos aspectos técnicos hidráulicos e hidrológicos.

Certamente, a implementação de um mercado de águas no Ceará, ou em qualquer Estado do Brasil, requer análises outras, sob os pontos de vista social e legal. Vale ainda salientar que a implementação do mercado de águas deve ser precedida pela total organização do setor de outorga. Essa organização deve constar de:

- avaliação completa das disponibilidades hídricas a alocar (outorgar);

- avaliação dos direitos de usos de água já estabelecidos;

- promoção da alocação inicial das disponibilidades hídricas de forma a instituir os direitos de curto prazo e de longo prazo visto que, por enquanto, nos termos da Lei 9.433/97 não existem direitos de água permanentes;

- definição de instrumentos legais que permitam as realocações dentro da estrutura de mercado.

Um importante ponto a se considerar no estudo diz respeito à ampliação dos conhecimentos dos regimes hidrológicos das diversas bacias hidrográficas do Estado.

Não se deve desconsiderar também a necessidade de uma ampla discussão com a população sobre os limites da aplicabilidade do mercado de águas, posto que, como colocado por Simpson (1993), uma das condições necessárias ao estabelecimento de um mercado de águas é a sua aceitação pela sociedade.

\section{AGRADECIMENTOS}

Os autores agradecem à FINEP pelo suporte financeiro provido através do projeto RECOPE/ REHIDRO. Agradecem também aos revisores da ABRH pelas pertinentes sugestões que contribuíram para o enriquecimento do presente artigo.

\section{REFERÊNCIAS}

ARAÚJO SÁ, J. A. C. e CAMPOS, L. R. (2001). O direito e a gestão das águas. Em: Campos, J. N. B. e Studart, T. M. C. Gestão de Águas: Princípios e Práticas, p.182. Porto Alegre: Associação Brasileira de Recursos Hídricos.

BHATIA, R.; CESTTI, R. \& WINPENNY, J. (1993). Water conservation and reallocation: "best practice" cases in improving economic efficiency and environmental quality. World Bank Technical Paper. Washington D.C., USA.

BRITO, F. W. C. (2001). O mercado de água da fonte batateiras no Cariri e a nova política de águas no Ceará: desafios da transição. Universidade Federal do Ceará. Dissertação de Mestrado.

BROOKS, D. B. (1997). Water demand management: conceptual framework and policy implementation. In: Planning workshop: water demand management research networking in Africa and Middle East, Cairo, Egypt.

CAMPOS, J. N. B. e VIEIRA, V. P. P. B. (1993). O gerenciamento dos recursos hídricos: a problemática do Nordeste. Revista de Administração, vol. 27, abr/jun, p.83-91.

CAMPOS, J. N. B. \& STUDART, T. M. C. (2000). An historical perspective on the administration of water in Brazil. Water International, vol. 25, $\mathrm{n}^{\circ} 1$, March, p.148-156.

EASTER, W. E. (1986). Irrigation investments, technology and management strategies for development. Studies in Water Policy and Management, ${ }^{\circ} 9$. Chapter 11, Westview, Boulder, Colorado.

EASTER, W. E. \& HEARNE, R. R. (1995). Water markets and decentralized water resources management: international problems and opportunities. Water Resources Bulletin, vol. 31, n 1 , February, p.9-20.

HEARNE, R. R. \& EASTER, W. E. (1995). Water allocation and water markets: an analysis of gains-from trade in Chile. World Bank Technical Paper, $\mathrm{n}^{\circ} 315,75 \mathrm{p}$. Washington D.C.

HEARNE, R. R. \& TRAVA, J. L. (1997). Water markets in Mexico: opportunities and constraints. International Institute for Environment and Development. Discussion Paper 97-01, London, 27p.

KEMPER, K. E.; GONÇALVES, J. Y. B. \& BEZERRA, F. W. B. (1999). Water allocations and trading in the Cariri 
Region - Ceará Brazil. World Bank Technical Paper $\mathrm{n}^{\circ}$ 427. Washington D.C., USA.

LANNA, A. E. L. (1994). Cobrança e mercados de água como instrumentos de gerenciamento dos recursos hídricos no Semi-Árido do Nordeste Brasileiro. In: II Simpósio de Recursos Hídricos do Nordeste. Fortaleza.

QUEIRÓZ, E. A.; VIEIRA NETO, J. e BOTELHO, M. A. (2000). Balanço hídrico distribuído na bacia do Rio Jaguaribe utilizando o sistema de informações geográficas. Em: V Simpósio de Recursos Hídricos do Nordeste. Natal, RN.

SIMON, B. \& ANDERSON, D. (1990). Water auction as an allocation mechanism in Victoria, Australia. Water Resources Bulletin 26 (3), June.

SIMPSON, L. (1993). Factors prerequisite to market-based transfers of water. Trabalho não publicado. World Bank. Washington D.C., USA.

\section{Water Rights Allocation and Reallocation: A Market-Based Model Limited in Space}

\section{ABSTRACT}

The search for an efficient water allocation for the growing demands has led to seeking new water management models. One of these models, the Water Market, practiced in several parts of the world, such as Chile, Australia and the western United States, has been the subject of much debate and controversy. This paper presents some theoretical concepts of allocation and reallocation processes and analyses several situations where a Water Market could increase water use efficiency.

Key Words: water management; allocation water. 